\title{
El acto performático como expresión del pensamiento en obras realizadas por artistas venezolanos
}

\author{
Sifontes, Maria A.
}

Resumen: El presente artículo hace el análisis de la puesta en escena del cuerpo del realizador y el manejo de los soportes tecnológicos como intervención en la construcción de la imagen y el discurso en cuatro obras audiovisuales realizadas por artistas venezolanos: A propósito de la luz tropical, Homenaje a Armando Reverón (1978) de Diego Rísquez; Bolívar, sinfonía tropical (1980) de Diego Rísquez; Que en Pez descansa (1986) de Nela Ochoa y TV Documental (2005) de Alexander Apóstol. El punto de partida es un breve recorrido histórico de la práctica del performance en los años 60 en un arte vivo y la influencia del video. Los artistas comenzaron a experimentar nuevos modos de expresión desde el espacio íntimo y pensamiento subjetivo. El uso de los soportes permitió nuevas tendencias y modos de representación, desencadenando la crisis de la subjetividad de las obras y las diferentes connotaciones del cuerpo. Se desarrolla un marco teórico Yo-imagen/ cuerpomáquina- imagen conectando la aparición del video que estalla la creatividad y en pensar la exposición del cuerpo frente a la cámara, dando pie al video-performance como acto de producirse a sí mismo y sus modalidades. El análisis de las obras seleccionadas y sus distintos soportes tecnológicos nos dan otra lectura de (de)construcción de las imágenesmemoria, imágenes-recuerdo en la experimentación del cuerpo expuesto o el cuerpo ausente para transmitir y comunicar una idea.

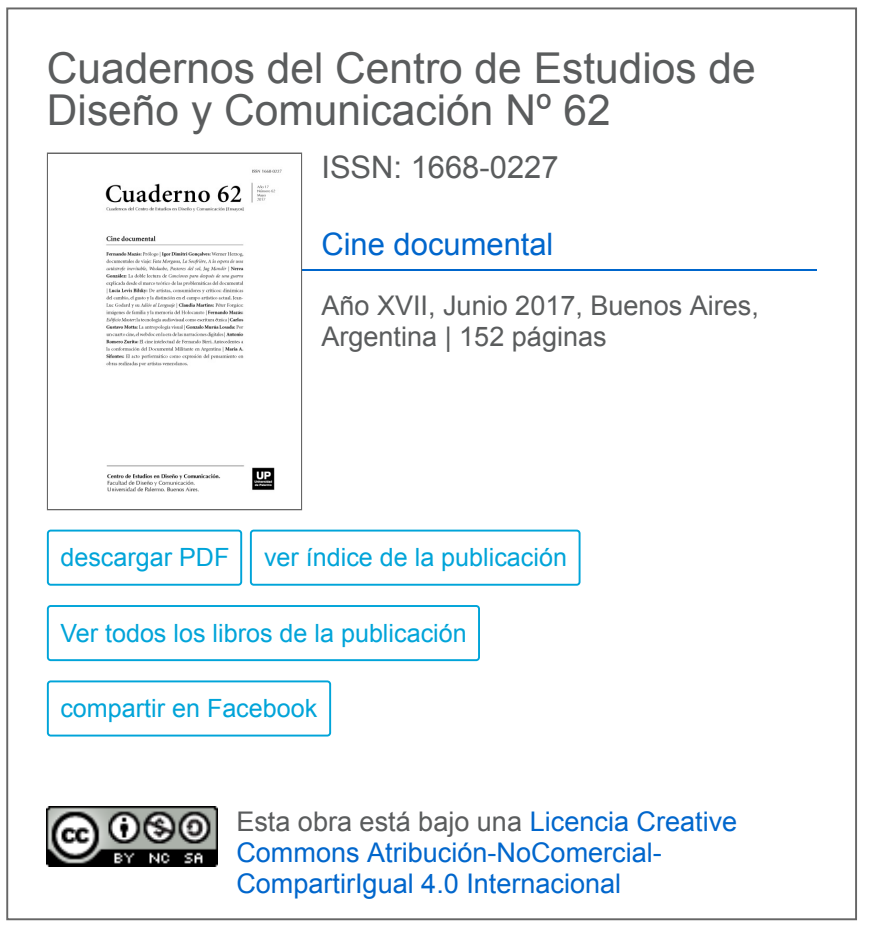

Palabras clave: Performance - video - cuerpo - máquina.

(*) Antropóloga (UCV). Desde el 2011 ha trabajado como productora e investigadora de la televisora comunitaria ViVe TV en Venezuela. Su tema de investigación se ha orientado al uso de lo audiovisual en el campo de las ciencias sociales. Actualmente está finalizando sus estudios en la Maestría de Cine documental (FUC), en la que orienta su investigación al análisis de la práctica documental y la producción intersubjetiva de la puesta en escena.

Para muchos historiadores y artistas, la performance se refiere a una forma específica de arte, arte en vivo o arte acción, que surgió en los años sesenta y setenta para romper con los lazos institucionales y económicos que excluían a artistas de espacios de exhibición. De manera repentina un performance podía surgir en cualquier sitio, en cualquier momento.

El artista sólo necesita su cuerpo, sus palabras, la imaginación para expresarse frente a un grupo de espectadores. El arte de la performance se expone a partir de una puesta en escena que permite estructurar lo que se quiere expresar, aunque su versatilidad puede ser meticulosamente planificada o espontánea. La diferencia es que el creador interpreta su obra, a diferencia del teatro que se representa mediante un actor. Lo importante de la performance es que los realizadores y los espectadores siempre están involucrados en un intercambio directo y en una relación interactiva.

(...) La performance puede ser una serie de gestos íntimos o teatro visual a gran escala, que dura desde unos pocos minutos hasta muchas horas; puede representarse sólo una vez o repetirse varias veces, con o sin un guión preparado, improvisado de manera espontánea, o ensayando durante muchos meses (...) (Goldberg,1979, p. 8)

Esta nueva tendencia de arte vivo y/o arte acción se caracterizó en los años 60 por el contenido, más que por el producto en si mismo, llamado arte conceptual más no comercial. La performance es un medio permisivo y sin límites de interpretación por parte del creador.

Por ello se expone y se interviene el cuerpo para transmitir y comunicar una idea.

Esta práctica en las últimas décadas ha jugado con la re-presentación, la transmisión de conocimiento mediante los gestos corporales, con la mirada del espectador y con el uso del espacio y tiempo, potencializando el discurso social. Esto se fue convirtiendo en el contenido de un gran número de obras que hacen referencias autobiográficas, dando pie a varios artistas para recrear momentos de su propia vida, manipulando o transformando los materiales en performance mediante el video, sonido, filme, etc., de manera que se incluía la descripción de su propia producción, autorreferencial. 
"(...) Las performances autobiográficas eran fáciles de seguir y el hecho de que los artistas revelaran información íntima acerca de ellos mismos establecieron una empatía particular entre el intérprete y el público". (Goldberg, 1979, p. 174)

El videoarte es una alternativa más económica a la producción tradicional en cine. Es una propuesta enfocada a personas que rompen con los parámetros comerciales y buscan un medio más económico, no por este motivo tiene menos valor conceptual que las formas tradicionales de producción.

El soporte en video permitió a los artistas adentrarse en su intimidad y en el autorretrato, convirtiéndose en material artístico y de investigación. La performance se trasladó al video-performance cuando el cuerpo del realizador y la máquina entran en un diálogo íntimo -espacio privado- de confrontación de su imagen y su cuerpo. Esta intimidad donde la cámara juega un papel invasivo, coloca al espectador en una relación intimidante. Los autorretratos no son solamente un doble, un reflejo o proyección de la personalidad, sino también su emanación, criatura del yo, su cuerpo imaginado.

En este sentido, surge el interés de trabajar con obras de artistas venezolanos que nos permitirá analizar la relación del cuerpo en intervención y/o el cuerpo en representación de la producción de contenido cultural. El criterio de la selección fue basado en los diferentes modos de construir un discurso mediante la exposición del cuerpo y la relación con los dispositivos tecnológicos y cómo estas representaciones se articulan con el cine documental.

Las obras seleccionadas son: A propósito de la luz tropical, Homenaje a Armando Reverón (1978) de Diego Rísquez; Bolívar, sinfonía tropical (1980) de Diego Rísquez; Que en Pez descansa (1986) de Nela Ochoa y TV Documental (2005) de Alexander Apóstol.

Yo-imagen / cuerpo-máquina-imagen

El cuerpo es el medio para contarme o decir quien soy yo (Bellour, 2004). Pero en sí ¿qué es el cuerpo? ¿el cuerpo identifica quién soy? ¿el cuerpo es un mediador social? ¿el cuerpo al orden social? ¿el cuerpo como imagen? o ¿la imagen del cuerpo? Los artistas comenzaron a generar una serie de preguntas cuando en el siglo XIX la definición del sujeto universal o totalizado pierde su fuerza al entrar la discusión de la "crisis del yo", la "crisis de la subjetividad". El sujeto se comienza a pensar en su corporeidad y la subjetividad inscripta en el cuerpo.

El cuerpo del artista toma otros enfoques dentro de la experiencia con las nuevas tecnologías, abriendo un abanico de formas de pensar el cuerpo en escena. La aparición del video permitió estallar la creatividad y pensar en la exposición del cuerpo frente a la cámara, dando pie al video-performance como acto de producirse a sí mismo.

Para Schefer (2008), el video construye una relación entre el cuerpo y la máquina, pero este no representa un sujeto capturado, visualizado, escuchado, etc., más bien, representa un sujeto dentro de los parámetros técnicos y estéticos que juega con la interacción entre lo tecnológico y lo subjetivo, por lo que es transversalmente penetrado y decodificado de

interfaces de representación entre cuerpo-máquina. Esta manera de representar el cuerpo se ha sostenido en la transformación de la concepción del cuerpo desde la "subjetividad" moderna, como anuncia Schefer1, el cuerpo-máquina como cuerpo cibernético, informativo, electrónico, como red de comunicación en la continua reproducción efectiva de señales mediante los nuevos dispositivos tecnológicos de representación.

La manipulación de los dispositivos tecnológicos construye una imagen técnica, desde la perspectiva de Vilém Flusser. Este gesto articula conceptos entre la mirada y el dispositivo "El aparato obliga al fotógrafo a transcodificar su intención en conceptos, antes de poder transcodificarlas en imágenes"2. Esto implica que tiene una contingencia histórica y ontológica diferente de la imagen tradicional. Según el autor la imagen tradicional es más fácil distinguirla porque existe un agente humano (pintor, diseñador) que se coloca entre ellas en lo simbólico y el significante. En cambio la imagen técnica no es tan sencilla porque existe un factor que se interpone entre la imagen y su significado. En este sentido, las imágenes en video asumen una nueva dimensión en la interacción entre el cuerpo y el dispositivo de registro en la transformación de los conceptos.

El video en principio viene asociado a la estética de la imagen, omitiendo el video como dispositivo -el dispositivo video como medio de comunicación-. El video-imagen, según Dubois (2001) actúa en la dimensión del lenguaje, la dimensión del proceso y la pragmática, en ésta separación, "ocupa una posición difícil, inestable, ambigua: ser a la vez objeto y

proceso, imagen-obra y medio de transmisión, a la vez noble e innoble, privado y público". (Dubois, 2001, p. 34)

La tecnología del video desencadenó que los autores comenzaran a exponer su cuerpo en imagen -el cuerpo como materia prima del dispositivo tecnológico3-. Nam June Paik se considera como el primer artista que explora las técnicas del video como dispositivo de transmisión y el uso del cuerpo. En trabajos como Global Groove (1973), Paik buscó estrategias de relatos que no fueron lineales y utiliza el video en sintonía con el cuerpo en acción, realizando actos performáticos que se desprenden de la narración. Desde la utilización de cuerpos danzando, exploración de las texturas de la imagen y su distorsión, pone en jaque el video como un soporte manipulable y también como soporte constante del cuerpo performático y mediatizado. Las tecnologías de la imagen y de la información lanzan una sombra ontológica sobre el cuerpo-carne que se pone en escena en el autorretrato, dejando en otra dimensión el cuerpo-imagen. En este sentido, Vito Acconci en Waterways: 
4 Saliva Studies (1971), en un primer plano presenta la relación intima con la cámara en su indagación con las propiedades de la saliva como fluido corporal. La performance, en este sentido es provocadora. El autor intensifica la puesta en escena para que el espectador se introduzca en su cuerpo.

Las primeras producciones en video permitieron que los artistas abordaran acciones, que hasta ese momento no se habían explorado con otros dispositivos tecnológicos (fotografía y cine), siendo esta primera tendencia artística caracterizada por la búsqueda del contacto corporal, sea en el enfrentamiento con otras personas o con la propia cámara. La puesta en

escena del sujeto del autorretrato se encuentra en la búsqueda por hallar nuevas formas de abordar el análisis del espacio autobiográfico cinematográfico. En contraposición el cuerpo en el video y la experiencia del "acto vivo". Bellour (2004) en su libro Entre-imágenes expone las razones para que se piensa el autorretrato en esta nueva era:

1. La imagen en continuidad, inmediata en la pantalla de la cámara de registro, en un doble real que no se detiene;

2. El video permite que el autor exhiba su intimidad con el dispositivo, haciendo que el cuerpo entre en la imagen sin dificultad por la ausencia de testigos;

3. El video traduce la mirada perceptiva del autor, los movimientos del cuerpo y los procesos de pensamiento.

El performance en el campo de las artes se relaciona directamente con la exposición e intervención del cuerpo para transmitir y comunicar una idea. El cuerpo humano (mi cuerpo) se vive de forma intensamente personal, producto y copartícipe de fuerzas sociales que lo hacen (in)visible. El trabajo de Valle (2011) identifica algunas características que

evidencia el acto performático en el documental y las menciona de la siguiente manera:

1. La experiencia vivencial, como registro de un proceso que ocurre durante el mismo momento del registro.

2. El carácter de intervención cuando el realizador o el sujeto registrado intervienen directamente en el espacio o en su relación frente a determinada persona o grupo de personas.

3. La relación que establece la cámara como sujeto que posee plena conciencia de lo que representa o deja que el soporte lo represente.

4. La relación entre la realidad y la creación de una realidad "representar una realidad se vuelve un concepto transitorio y subjetivo a partir de las estrategias de abordaje que determinan por incentivar el diálogo entre realidad y lo imaginario.

El cuerpo del realizador al intervenir en el proceso, da la posibilidad de establecer una relación más intima entre el realizador y el soporte de video, el autorretrato se volvió un principal modo de práctica documentalista. Es el caso de los trabajos en video de Robert Kramer, en Berlín 10/90 (1990) decide exponer su cuerpo directamente a la cámara en un

plano secuencia de sesenta minutos, en el baño de una habitación. Aislándose del lugar y conectándose al mundo exterior mediante un televisor prendido. Kramer realiza una reflexión del retorno Alemania y refleja su historia familiar. Kramer genera un efecto de agotamiento en la confrontación con la cámara de video que toma un rol de cámara de vigilancia.

En este sentido, la relación entre el video y cuerpo se afirma en el documental. Lo performático no solo necesita de la acción, sino del todo de la acción en una relación con el otro, en un contexto social e histórico determinado, y no es únicamente la afirmación del realizador sino el acto o el proceso de intervención que se establece sobre el pensamiento.

Por otra parte, el acto performático se realiza detrás de la cámara. Una cámara subjetiva, donde el realizador interviene en la interacción con el otrointerlocutor- en el preciso momento del registro. Esto enfatiza con mayor fuerza la subjetividad y termina realizando una unión entre el cuerpo del realizador en acción y la cámara como prótesis de ese cuerpo y de su mirada.

La materialidad del pensamiento

La puesta en escena como concepto se encuentra sin límites establecidos, debido a que este término fue una transferencia del teatro al cine y ha tomado muchos modos de interpretarse.

Por ello, partiendo de la formulada de la puesta en escena por Eduardo Russo4 destacamos:

La función de la mirada transciende desde allí lo expuesto a la visión, haciendo así a la puesta en escena una operación generadora de una serie de revelaciones momentáneas, producidas cuando las imágenes se forman, confluyen y establecen sus relaciones, tanto como plantean sus interrogantes 
(...) la puesta en escena poseedora de un notable efecto de irrupción en su capacidad significante - de todo un tejido audiovisual que allí arriba a su condición de función-signo. (p. 56)

La construcción de significante mediante un recorte visual que impone el autor. Esta elección también considera-dependiendo de que tipo de film-que se constituya un recorte, es decir, lo que ocurre dentro del plano con los aspectos más técnicos y estéticos de iluminación, actuación, escenografía, etc., da mayor énfasis el espacio-tiempo del plano. Este

recorte de la mirada se relaciona al autor frente de la cámara y tiene un compromiso con el espectador, porque precisamente éste se integra a ella. En la mirada del espectador se habilita la misma escena, se expone el pensamiento del autor.

La mirada desde el dispositivo de video se limita por los planos y el montaje. Recordemos que el plano no es solamente la unidad base de un lenguaje audiovisual, sino un bloque de espacio y tiempo que sirve como núcleo en todo el film. En términos de Dubois (2001) el plano es lo que funda la idea del sujeto en el cine,

un plano se constituye a partir de un cierre (cuadro) y de una exterioridad (el fuera de campo), que posee una profundidad (el campo) homogénea y estructurada (...), y que instituye un punto de vista (ligado a la perspectiva) a partir del cual el Todo se define. (p. 36)

El montaje lo entendemos como la disposición y encadenamiento de los planos que construyen la continuidad del lenguaje audiovisual. Este instrumento establece la fuerza expresiva de la práctica videográfica. Esta dialéctica conceptual construye la puesta en escena en su totalidad.

La expresión del pensamiento del acto performático mediante los soportes técnicos

El siguiente análisis se enfocará en la puesta en escena del cuerpo del realizador y la construcción del discurso mediante los dispositivos tecnológicos empleados. Solo como dato contextual, cada obra expone una interpretación del artista acerca de la historia de Venezuela, desde los tiempos de la independencia en la obra de Bolívar, una sinfonía tropikal (1980) de Diego Rísquez, pasando por el Homenaje a Armando Reverón (1978) del mismo director en un acto performático en la construcción interactiva con el personaje. Hasta alcanzar una interpretación de la realidad más contemporánea en Que en pez Descanse (1986) de Nela Ochoa y el corto TV documental (2005) de Alexander Apóstol en una lectura más reciente de la sociedad venezolana. Este corpus de películas, nos conduce a destacar los distintos soportes tecnológicos y su relación con cine documental.

Bolívar, una sinfonía tropikal (1980) de Diego Rísquez

Me interesa resaltar cómo el soporte tecnológico influye en la puesta en escena y cómo se expresa la imagen-pensamiento del artista. Este film fue realizado por una cámara súper 8 , su imagen fotoquímica que remite a la memoria receptiva. Es así, como el director utilizó el dispositivo como un pincel, haciendo que la luz dibuje sobre los celuloides. La tinta se compone de luz que entra al dispositivo tecnológico permitiendo que su reacción química se fije en el material fílmico. Esta película representa trazos de las imágenes mentales de la memoria histórica del director Diego Rísquez. "Se acercan a la imagen que uno puede escribir, cuando uno la dibuja con una cámara transformada en pincel de luz, o con una paleta grafica y una computadora". (Bellour, 2004, p. 284)

La puesta en escena se construye de planos generales fijos en representación de las pinturas históricas venezolanas en una puesta teatral-ficcional. Los planos detalles con cámara en mano presenta a los personajes que forman la pintura. La imagen fotoquímica se quiebra cuando el soporte queda en evidencia del espectador, los actores dirigen su mirada directa al dispositivo tecnológico generando una percepción de transgresión, ya que es una particularidad del video como algo natural que se traslada a lo televisivo.

La banda sonora esta compuesta de la ausencia del diálogo y la recreación de nueva música.

En este sentido, las características físicas del soporte permitió la composición de la puesta en escena, ya que el dispositivo se puede movilizar con facilidad. No existe un registro sincronizado entre imagen y sonido. Lo interesante de la materialidad de este film es, primero: la presencia no continua de la imagen por las características del registro; segundo: la imposibilidad de visualizar en el momento lo que se estar filmando; y tercero: no hay sonido directo, la composición sonora se realiza en la edición.

En mi opinión, la elección de esta puesta en escena como acto performático permite una reapropiación de la pictografía de la historia de Venezuela en la construcción de las imágenes recuerdo. Por otra parte, activa la mirada del espectador en dar cuenta que se filma cuando los actores interactúan con la mirada directa al dispositivo tecnológico, humanizando la mirada de la cámara.

Siguiendo con los postulados del autorretrato en términos de Bellour (2004), la impresión subjetiva se precisa cuando el cuerpo del que filma se entrega en la imagen. La puesta en escena ficcional anuncia un relato poético y reflexivo en las imágenes mentales de Rísquez, entendiendo este como un acto perfomático fuera de campo.

Esto nos lleva a preguntarnos ¿cuál es el lugar donde se traslada ese cuerpo fuera de campo, ausente, en efecto de la imagen, el efecto de la impresión de la imagen y la música que la acompaña? El lugar "real", según Bellour (2004), lo sustenta el funcionamiento de la memoria partiendo de un modelo arquitectónico y en los lugares "analíticos" construidos por secuencias de operaciones lógicas que sostienen la dialéctica. Este espacio-temporal se 
anuncia en un escenario del mar costeño del caribe (lugar de nacimiento del director) y la memoria histórica. En este sentido se puede pensar como autorretrato desde las imágenes-recuerdo.

La imagen-recuerdo es una imagen compuesta, que se despliega según múltiples niveles, a merced de cadenas asociativas que tienden tanto a constituir esos niveles, como otros tantos estratos autónomos, lugares identificables, como a pasar de uno a otro por medio de un movimiento imprevisible y $\sin$ fin. (Bellour, 2004, pp. 315-316)

Rísquez se apropia de las pinturas en su representación en el proceso de resemantización subjetiva, en este caso no es material de archivo sino de pinturas, dándole otra lectura al retrato histórico de Venezuela. A nivel más técnico, la velocidad de exposición de ciertas secuencias, el director propone un nuevo modo de mirar al espectador, de la pintura al cine. Por ejemplo, la representación de la firma del acta de independencia 1810 y Francisco de Miranda en la carraca. El interés es hacer una contraparte del cine documental histórico que se fundamenta en el estudio dominante de documentos históricos.

Desde mi perspectiva, no se trata de una puesta en escena del discurso directo sino en un filmensayo-experimental donde existe una hibridez de recursos narrativos omitiendo el componente de la voz y en la utilización del acto performático como representación de la memoria individual. Por ello, la nueva representación re-significación el espacio mental mediante el acto performático construye el mundo de sentidos y la expresión del pensamiento del realizador, lo que se puede considerar como autorretrato dentro del campo del cine documental contemporáneo. "(...) el autor se enuncia y expone al aparato tecnológico como un bloque de cuerpo, memoria, pensamiento y experiencia (...)" ( Schefer, 2011, p. 2)

A propósito de la Luz Tropikal, Homenaje a Armando Reverón (1978) de Diego Rísquez

Esta película fue realizada en un soporte de Súper 8 -al igual que el film que se presentó anteriormente-. El dispositivo le da cierta personalidad al director y el uso de la cámara como pincel que dibuja con la luz. Lo interesante es cómo el realizador utiliza el dispositivo tecnológico como medio de expresión en la sobreexposición de luz. La materialidad no tiene ninguna modificación en la edición, lo que permite evidenciar la importancia de pensar la imagen a través del soporte de registro y la intención de lo que se quiere expresar y experimentar.

Siguiendo con el acto performático, este film desde mi opinión, representa dos instancias de referencia en la construcción de la primera puesta en escena al componerse de la exposición del cuerpo del artista Armando Reverón en la acción de dibujar en el lienzo -plena construcción de la imagen tradicional en términos de Vilem Flusser-. La segunda, el rol que toma el dispositivo tecnológico -súper 8- como pincel desde la subjetiva del director imagen técnica según Flusser-. En este sentido, se podría interpretar como dos representaciones que se construyen en una mediante la hibridez de la imagen-mental en diferentes expresiones de los soportes.

Desde mi punto de vista, estas obras son autorreferenciales porque desarrollan un espacio mental en la apropiación de pinturas o artistas que representan un momento de la vida del Director Diego Rísquez. Éste espacio mental lo construye la experimentación del pincel como cámara, el relato no continuo, pensar en imagen y su percepción. Al igual que la película Bolívar, sinfonía tropikal no utiliza el diálogo, sino la música experimental.

El espacio y tiempo se contextualiza en un lugar íntimo de la cotidianidad de Reverón. Un relato no continuo expone la representación del pensamiento del realizador mediante el acto performático que crea con el personaje.

En este sentido, Pérez Ornia nos resumen que la performance se diferencia:

(...) respecto al cine y la televisión se evidencian en el diferente uso que los artistas hacen de la tecnología. Muchas de estas obras no están editadas. Coinciden el tiempo real y el tiempo de la imagen. Adolecen de un lenguaje cinematográfico primario: largos planos secuencias en los que la cámara no modifica su posición; inexistencia de planificación, pobreza, en fin de los recursos propios de la imagen. (1991, p. 79)

La hibridez de la exposición del cuerpo y su producción como estrategia de contar quien soy, ha permitido a los artistas hacer su representación del pensamiento que se determina de acuerdo al dispositivo tecnológico que usan.

Que en pez descanse (1986) de Nela Ochoa

El pasaje del fotoquímico al video electrónico ha alterado la ontología de la imagen en movimiento, por ello se presentaron primero los films de soporte fílmico y luego los de video dándole una continuidad a los cambios de los soportes tecnológicos audiovisuales.

Este cortometraje se diferencia de los anteriores por el uso del video como soporte. El video construye imágenes electrónicas que se superponen a la percepción óptica. Esta puede ser intervenida estéticamente dependiendo de lo que se quiera expresar. Este soporte le permitió a artistas nóveles la experimentación de nuevas modalidades de representación

y de expresión desde la estética. El acto performático se evidencia en la representación de una realidad de la iglesia católica mediante un concepto subjetivo de la religión católica que se transcribe en la puesta en escena y el dispositivo. 
La puesta en escena se compone en el acto ficcional, la composición de la banda sonora y el uso de sobreimpresión en la imagen electrónica modificando la percepción del espectador.

La realizadora expone su crítica mediante los cuerpos expuestos y la sobreescritura.

El discurso discontinuo va construyendo la película. El espacio se articula en un pasado y un presente que se cruzan en un mismo lugar.

Las imágenes se intervienen mediante los colores y el movimiento lento para darle mayor intensidad al relato no continuo. Se recrea el espacio mental de la realizadora, en la sobreimpresión de los pies de una mujer adulta y los pies de una niña que es un personaje vidente de la situación establecida en el espacio. El video permite construir un montaje horizontal -en términos de Schefer- para no leer la imagen como un referente temporal, sino como el proceso de asociación dialéctica de la materialidad de un concepto abstracto a través del montaje conceptual. "el video piensa lo que el cine crea". (Phillipe Dubois)

TV Documental (2005) de Alexander Apóstol

Se expone de último porque su soporte es video digital. Un cortometraje más contemporáneo donde el realizador Apóstol desarrolla un espacio mental y simbólico en la reflexión subjetiva de las desigualdades y el engaño y manipulación mediático.

El soporte de video digital permite hacer otro tipo de lectura, donde el espacio se recrea en la intimidad. La puesta en escena se presenta en un espacio físico con sus personajes: un padre y sus dos hijos viendo la televisión. En la voz del locutor del sonido diegético del televisor contextualiza la obra. Inicia un giro de 360 grados por el espacio en plano secuencia, donde toma mayor ritmo en la medida que avanza la música del espectáculo. Se detiene el giro y se repite varias veces, mientras el sonido de la locución expone el llamado progreso en Venezuela de los años 70 y la música del espectáculo. La imagen electrónica permite que el realizador pueda manipular su velocidad para intensificar la recepción. En

este sentido, se abre un espacio a través de la cámara y el computador que procesa esta mirada, para permitir que atravesemos estas imágenes. El movimiento advierte que es una situación dialéctica. Esta situación que se genera en el cruce entre el cine y el video.

(...) la imagen televisiva se afirma como tal cuando revela su naturaleza electrónica, cuando las elaboraciones de los sintetizadores y los efectos especiales tornan explicita su forma de construirse y mostrarse; esta fue la dirección tomada por los videoartistas que hace veinte años trabajan para desvelar la esencia de las nuevas imágenes (...) (Pérez Ornia, 1991)

A modo de conclusión

El performance en el campo de las artes se relaciona directamente con la exposición e intervención del cuerpo para transmitir y comunicar una idea. Esta práctica en las últimas décadas han jugado con la re-presentación, la transmisión de conocimiento mediante los gestos corporales, con la mirada del espectador, el uso del espacio y los nuevos soportes de

registro potencializando el discurso social.

La performance desde los distintos soportes tecnológicos ha permitido indagar en la (de) construcción de las imágenes-memoria, imágenes-recuerdo en la experimentación del cuerpo expuesto o el cuerpo ausente en su interacción con los dispositivo tecnológico.

Entre el intercambio de la materia viva (cuerpo) y el artefacto de registro (cámara) que hace pensar la relación que existe en su uso.

En este sentido, las obras expuestas nos abre a comprender desde el acto performático la relación del cuerpo del realizador con el dispositivo y la construye el pensamiento abstracto en una lectura de historicidad pendiente. Por ello, inicié el análisis de las películas que fueron realizadas en Súper 8 -que coinciden con el mismo director- exponiendo la presencia del cuerpo desde la mirada y el uso del dispositivo, y como esta define ciertas características expresivas y receptivas que permite construir un metalenguaje. Luego el video ha facilitado la construcción de la imagen-memoria e imagen-recuerdo por ser electrónica transversalmente penetrado y decodificado de interfaces de representación entre cuerpo-máquina.

Notas

1. Schefer, Raquel (2008) El autorretrato en el documental: figuras/máquinas/imágenes. Buenos aires, Catálogos: Universidad del Cine.

2. Flusser, Vilém. El arte y la técnica. Hacia una filosofía de la fotografía. EdicionesTrillas México, 1990.

3. Schefer, Raquel (2008) El autorretrato en el documental: figuras/máquinas/imágenes. Buenos aires, Catálogos: Universidad del Cine.

4. "Cine: una puesta en otra escena, Quince años después”, Eduardo A. Russo, en Territorios audiovisuales.

Bibliografía 
Russo, E. "Cine: una puesta en otra escena, Quince años después", en Territoriosaudiovisuales. "Performance/Cuerpos imaginados", en El arte del video.

Bellour, R. (2004). “Autorretratos”. Entre imágenes. Buenos Aires: Ediciones Colihue.

Bernádez, C. (1999). Joseph Beuys. Madrid: Nerea.

Comolli, J-L. (2002). Filmar para ver. Escritos de Teoría y crítica de cine. Buenos Aires: Ed. Simurg.

Dubois, P. (2000). Cine, Video, Godard. Buenos Aires: Libros del Rojas.

Dubois, P. (2000). Máquinas de Imágenes: una cuestión de línea general, Cine, Video, Godard. Buenos Aires: Libros del Rojas.

Golberg, R. (1979). Performance art. Desde el futurimo hasta el presente. Ediciones destino. Jones, A. Body art/ performing the subject. Minnesota

López, M. (2006). "El video arte como soporte comunitario y creativo en la acción social, lucha política y arte integral”, Ana Mampaso en Creación y posibilidad: aplicaciones del arte en la integración social.

Schefer, R. El autorretrato en el Documental. Figuras/Máquinas/Imágenes. FUC/Ediciones Universidad del cine/Catálogos, Buenos Aires, 2008

Valle, R. (2011). El yo es otro. Estudio sobre el acto performático y el cine documental brasilero contemporáneo. Trabajo de tesis. Universidad del cine.

Costa, Mario. La televisión, in L’Estetica dei Madia: Tecnologia e Produzione Artistica, Lecce,capone editores, 1990.

Abstract: The article analyzes the staging and the application of technological devices in the construction of the image and the discourse in four audiovisual works due to Venezuela's artists: Related to tropical light, hommage to Armando Reverón (1978) by Diego Rísquez; Bolívar, tropical shymphony (1980) by Diego Rísquez; Rest in fish (1986) by Nela Ochoa and TV Documentalry (2005) by Alexander Apóstol. The starting point of the paper is a brief historical tour of the practice of performance in the sixties and the influence of video. Artists began to experience new ways of expression from the intimate space and the subjective thought. The use of devices has allowed new trends and ways of representation and has unchained the subjectivity crisis of the works and the different connotations of the body. A theoretical corpus is developed (I - image/body-machine-image) connecting the birth of video and the exposition of the body in front of the camera, allowing the creation of the video-performance as an act of self-production. The analysis of the selected works and its different technological devices provides an approach of (un) construction of the images-memory, images-memoirs, in the exposed body experience or the absent body to communicate an idea.

Key words: Performance - video - body - machine.

Resumo: $\mathrm{O}$ artigo analisa a posta em cena do corpo do realizador e a gestão dos suportes tecnológicos como intervenção na construção da imagem e o discurso em quatro obras audiovisuais feitas por artistas venezuelanos: A propósito da luz tropical, Homenagem a Armando Reverón (1978) de Diego Rísquez; Bolívar, sinfonia tropical (1980) de Diego Rísquez;

Que em pez descansa (1986) de Nela Ochoa e TV Documental (2005) de Alexander Apóstol. O ponto de partida é um breve percurso histórico da prática da performance nos anos 60 numa arte viva e a influência do vídeo. Os artistas começaram a experimentar novos modos de representação, desencadeando a crise da subjetividade das obras e as diferentes conotações do corpo. Se apresenta um marco teórico Eu-imagem/corpo-máquinaimagem conectando a aparição do vídeo que explode a criatividade e em pensar a exposição do corpo frente à câmara, propiciando ao vídeoperformance como ato de produzir-se a se mesmo e suas modalidades. A análise das obras eleitas e seus diferentes suportes tecnológicos dão outras leituras de de(construção) das imagens -memória, imagens- lembranças na experimentação do corpo exposto ou o corpo ausente para transmitir e comunicar uma idéia.

Palavras chave: performance - vídeo - corpo - máquina.

El acto performático como expresión del pensamiento en obras realizadas por artistas venezolanos fue publicado de la página 115 a página126 en Cuadernos del Centro de Estudios de Diseño y Comunicación № 62 